\title{
Lung cancer what the surgeon needs to know
}

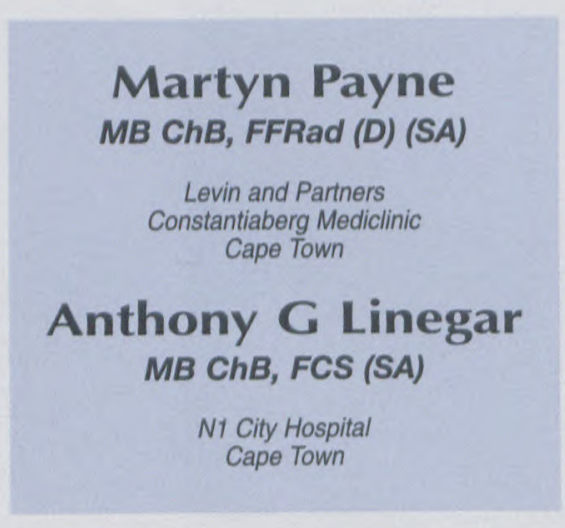

\section{Introduction}

Lung cancer is the commonest cause of death from cancer, accounting for over 900000 of the estimated 5.2 million cancer-related deaths worldwide. ${ }^{1}$ South Africa is the only developing country with a cancer death rate approximately the same as that of the developed world. ${ }^{1,2}$

Approximately $80 \%$ of lung cancers are categorised as non-small cell tumours (NSCLCA) and the rest $(20 \%)$ are small cell tumours. NSCLCA can be cytologically subdivided, with adenocarcinoma being the commonest $(40 \%)$ followed by squamous cell carcinoma (30\%) and large cell undifferentiated carcinomas $(10 \%)$. There are also tumours with mixed cell types where two different tumour cell types are identified in a single tumour (e.g. adenosquamous carcinoma).

Primary surgery is universally accepted as the treatment of choice in early stage (cStage I and cStage II)
NSCLCA in selected patients with the physiological reserves to undergo the operation and maintain a reasonable quality of life thereafter. The purpose of surgery is curative, and this requires careful patient selection if fruitless interventions are to be avoided. The overall cure rate after complete resection is $13 \%{ }^{3}$

\section{Staging}

Staging the tumour is crucial to planning of treatment, prognostication, and the final interpretation of the results of therapy. Non-invasive imaging techniques (i.e. spiral CT scanning with contrast enhancement) are used to determine the anatomical extent of the disease and thereby to enable clinical staging according to the tumour node metastasis (TNM) staging system. ${ }^{4}$ Clinical staging refers to staging prior to surgery and is prefixed by the letter 'c' (cTNM) whilst pathological staging (pTNM) refers to the pathological staging achieved by systematic surgical exploration.

\section{International staging system}

The TNM system (Table I) provides a reproducible description of the anatomical extent of the disease and was most recently updated in $1997 .{ }^{4}$ The $\mathrm{T}$ descriptor refers to tumour size, anatomical extent and relationship to adjacent structures. The $\mathrm{N}$ descriptor refers to extent of nodal disease. The $\mathrm{M}$ descriptor refers to presence or absence of metastases.

\section{Imaging assessment of Stage}

The chest radiograph (high $\mathrm{kVp}$ $120-130$, PA and lateral) is the way in which most lung cancers are detected and is useful in preliminary clinical staging. $\mathrm{T}$ criteria such as size and location of the tumour, atelectasis, pleural effusion and chest wall invasion with rib destruction can be assessed. However, it is insensitive to small nodules and to small to moderate sized lymph node involvement, and is unreliable in ascertaining extent of mediastinal invasion (Fig. 1). It is therefore insufficient in determining resectability extent in cases of clearly advanced disease.

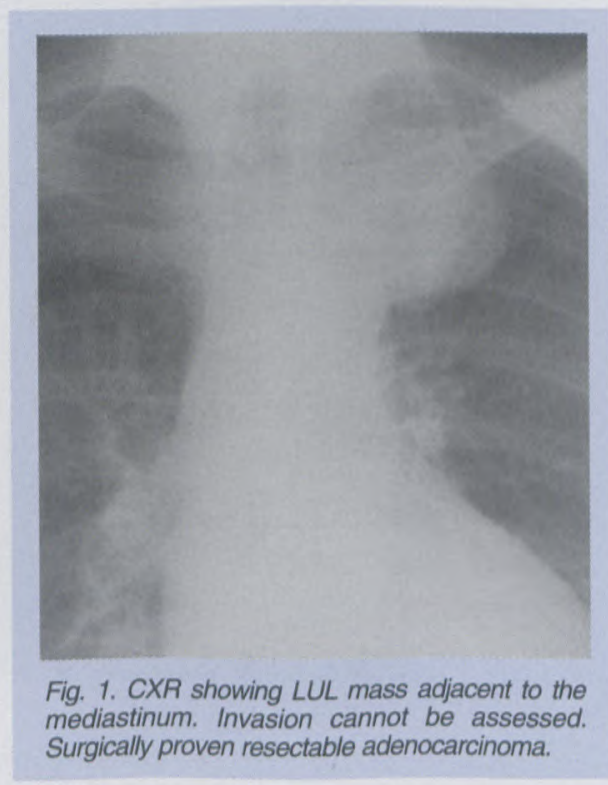

CT scanning is the dominant imaging modality and should be routinely performed. ${ }^{5}$ The examination must extend inferiorly to include the adrenal glands and liver, which are common sites of distant metastases. It should be performed with intra- 


\begin{tabular}{|c|c|}
\hline \multicolumn{2}{|c|}{ Tumour status ( $\mathrm{T}$ descriptor) } \\
\hline $\mathrm{Tx}$ & $\begin{array}{l}\text { Primary tumour cannot be assessed, or tumour proven by malignant } \\
\text { cells in sputum but not seen on imaging or bronchoscopy }\end{array}$ \\
\hline T0 & No evidence of primary tumour \\
\hline Tis & Carinoma in situ \\
\hline $\mathrm{T} 1$ & $\begin{array}{l}\text { Tumour } 3 \mathrm{~cm} \text { or less in greatest dimension, surrounded by lung or vis- } \\
\text { ceral pleura, without bronchoscopic evidence of invasion more proximal } \\
\text { than the lobar bronchus (i.e. not in the main bronchus)* }\end{array}$ \\
\hline $\mathrm{T} 2$ & $\begin{array}{l}\text { Tumour with any of the following features of size or extent: } \\
\text { More than } 3 \mathrm{~cm} \text { in greatest dimension } \\
\text { Involves the main bronchus, } 2 \mathrm{~cm} \text { or more distal to the carina } \\
\text { Invades the visceral pleura } \\
\text { Associated with atelectasis or obstructive pneumonitis that extends } \\
\text { to the hilar region and does not involve the entire lung }\end{array}$ \\
\hline T3 & $\begin{array}{l}\text { Tumour of any size that directly invades any of the following: } \\
\text { Chest wall (including superior sulcus tumours), diaphragm, } \\
\text { mediastinal pleura, parietal pericardium } \\
\text { Or tumour in the main bronchus }<2 \mathrm{~cm} \text { distal to the carina, but } \\
\text { without involvement of the carina } \\
\text { Or atelectasis or obstructive pneumonitis of the entire lung }\end{array}$ \\
\hline $\mathrm{T} 4$ & $\begin{array}{l}\text { Tumour of any size that invades any of the following: } \\
\text { Mediastinum, heart, great vessels, trachea, carina, oesophagus, } \\
\text { vertebral body } \\
\text { Or tumour with a malignant pleural or pericardial effusion }{ }^{\dagger} \\
\text { Or with satellite nodule(s) within the primary tumour lobe of the } \\
\text { lung }\end{array}$ \\
\hline \multicolumn{2}{|c|}{ Regional lymph nodes (N descriptor) } \\
\hline $\mathrm{Nx}$ & Nodes cannot be assessed \\
\hline N0 & No lymph node metastases \\
\hline $\mathrm{N} 1$ & $\begin{array}{l}\text { Metastases to ipsilateral peribronchial and or ipsilateral hilar lymph- } \\
\text { nodes, and intrapulmonary nodes involved by direct extension of the } \\
\text { primary tumour }\end{array}$ \\
\hline $\mathrm{N} 2$ & Metastases to ipsilateral mediastinal and or subcarinal lymph nodes \\
\hline N3 & $\begin{array}{l}\text { Metastases to contralateral mediastinal, hilar or scalene or } \\
\text { supraclavicular nodes }\end{array}$ \\
\hline \multicolumn{2}{|c|}{ Distant metastasis status (M descriptor) } \\
\hline $\mathrm{Mx}$ & Cannot be assessed \\
\hline M0 & No distant metastases \\
\hline M1 & Distant metastases present ${ }^{\ddagger}$ \\
\hline \multicolumn{2}{|c|}{ 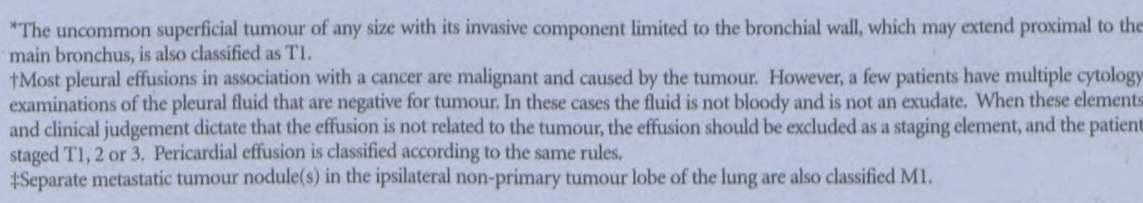 } \\
\hline
\end{tabular}

venous contrast to allow accurate differentiation of mediastinal and hilar vascular structures from nodal tissue and tumour. The scan must also be displayed with lung and soft tissue settings.

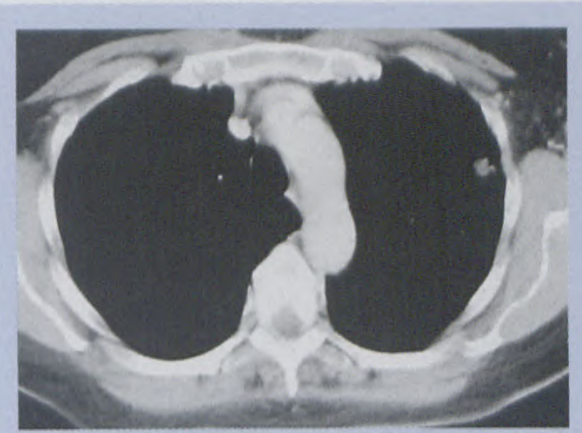

Fig. 2. CT of T1NO adenocarcinoma

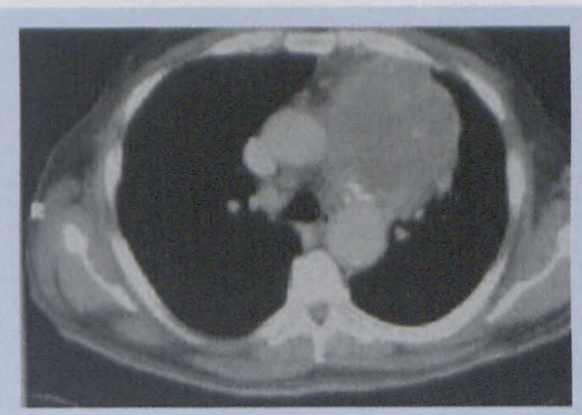

Fig. 3. CT showing obvious mediastinal invasion.

diagnosed, but it can be difficult to distinguish between tumour contiguity and extension into mediastinal structures (Fig. 3). Intact fat plane, contact of $3 \mathrm{~cm}$ or less with the mediastinum and less than $90^{\circ}$ contact with the aorta suggest no invasion, whereas greater than $180^{\circ}$ contact with the mediastinal structures usually indicates invasion.

\section{CT assessment of $\mathrm{N}$ descriptor}

$\mathrm{N}$ assessment relies on node size with a short axis diameter of greater than $1 \mathrm{~cm}$ being considered positive for nodal metastases (Fig. 4). However, small nodes can contain microscopic tumour deposits (producing a false-negative assessment in $20 \%$ of cases) and conversely large nodes may be clear of metastases (producing a false-positive assessment in $20 \%$ of cases for glands greater than $2 \mathrm{~cm}) .{ }^{6} \mathrm{~A}$ 


\section{REVIEW ARTICLE}

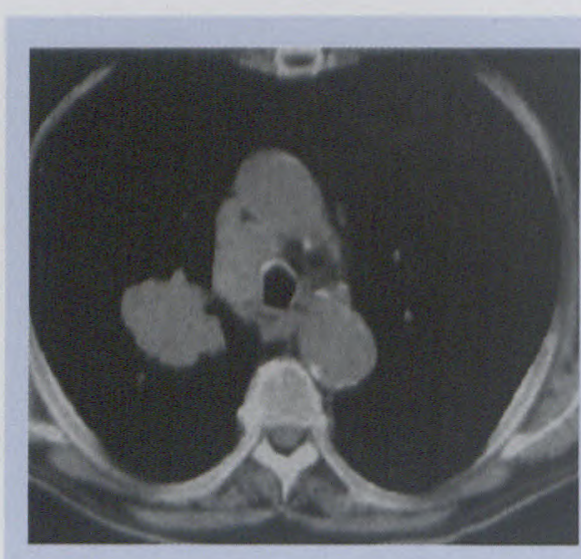

Fig. 4. T2N2: lymph nodes measure greater than $1 \mathrm{~cm}$ in short axis.

systematic approach using one of the accepted lymph node maps should be utilised to describe disease in hilar (N1), ipsilateral mediastinal (N2) and contralateral mediastinal (N3) stations. ${ }^{8,9}$

The profoundly negative impact on survival of nodal metastases is well documented, but the identification of hilar nodal (N1) disease remains a weakness in the clinical assessment.

\section{CT assessment of $M$ descriptor}

The search for metastases is initially limited to the chest and the upper abdomen unless clinical information indicates the need for brain and or bone scanning which are not routinely performed. Low density liver lesions are frequently encountered. These are most often benign cysts. Ultrasound can be useful in differentiating cystic from solid lesions. Isolated adrenal masses are usually benign adenomas. Unenhanced CT attenuation of $10 \mathrm{HU}$ or less, or more than $50 \%$ washout on 10-minute delayed enhanced CT are highly specific for benign adrenal adenomas. ${ }^{10}$

\section{MRI}

This is of similar accuracy to CT in assessing the $\mathrm{T}$ and $\mathrm{M}$ descriptors, but may offer an advantage over CT in assessing mediastinal and chest wall invasion, particularly in superior sulcus tumours. ${ }^{5}$ Chemical shift MRI accurately differentiates metastases from benign adrenal adenomas. ${ }^{11}$

\section{Positron emission tomography}

PET scanning relies on the increased metabolism of glucose in tumour cells to characterise glands and masses. Its role in routine preoperative staging is yet to be fully defined, but may prove to be useful in enhancing the CT assessment, in examining the $\mathrm{N} 1$ hilar nodes, and for evaluation of any contralateral parenchymal nodules. ${ }^{12}$

\section{Stage grouping}

Stage groups were developed on retrospective survival data. ${ }^{4}$

\begin{tabular}{|lll|}
\hline Stage & TNM subset & $\begin{array}{l}\text { 5-Year } \\
\text { survival (\%) }\end{array}$ \\
\hline 0 & Ca - in situ & \\
IA & T1N0M0 & 60 \\
IB & T2N0M0 & 38 \\
IIA & T1N1M0 & 34 \\
IIB & T2N1M0 & 24 \\
& T3N0M0 & 22 \\
IIIA & T3N1M0 & 9 \\
& T1N2M0 & 13 \\
& T2N2M0 & 13 \\
& T3N2M0 & 13 \\
IIIB & T4 any N & 7 \\
& N3 any T & 3 \\
IV & M1 any T, & \\
& any N & 1 \\
& & \\
\hline
\end{tabular}

The major prognostic factor is the ability to achieve a complete resection (R0). Limited invasion of the mediastinum or of the chest wall (T3) does not prohibit complete resection, and provided the mediastinal glands are not involved 5-year survivals of up to $40 \%$ can be achieved .

Pleural effusions in the presence of a lung tumour are almost always malignant and should be considered to be so unless careful cytological analysis of the fluid as well as thorough thoracoscopic examination reveals no malignancy in the pleural space. This is unlikely in advanced $\mathrm{T}$ and $\mathrm{N}$ categories. Malignant effusions confer a T4 status on the tumour and these patients are not surgical candidates.

The purpose of detecting mediastinal nodal disease preoperatively is to avoid unnecessary operations that will not favourably influence survival. Where large mediastinal glands are recognised on the CT scan, biopsy by mediastinoscopy and or mediastinotomy is undertaken, where these glands are within reach of the mediastinoscope. Mediastinoscopy will produce a false-negative result in $25 \%$ of cases. ${ }^{13}$

Clinical staging under stages the full extent of the disease in at least $25 \%$ of cases which explains why the overall 5-year survival in T1N0 is only $60 \%$ (i.e only $60 \%$ were in fact T1N0 and the rest had more advanced disease).

\section{Additional information}

Chest radiograph and CT scanning will provide other valuable information that may influence surgical plan- 
ning. Background lung disease such as COPD, scarring, likely presence of adhesions from previous pleural disease, and cardiac disease can be assessed and factored into the overall risk assessment for surgery (Fig. 5). The site and size of the tumour and some anatomical factors identified on the scan can assist in estimating the likely extent of the resection necessary to achieve a complete resection (i.e. lobectomy or pneumonectomy) (Fig. 6).

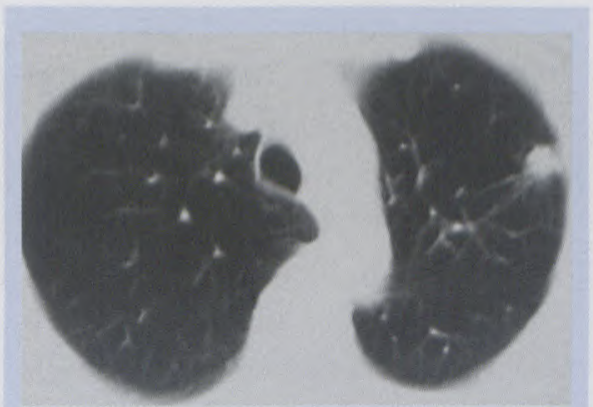

Fig. 5. T1 tumour, but note background of COPD which may complicate surgical approach.

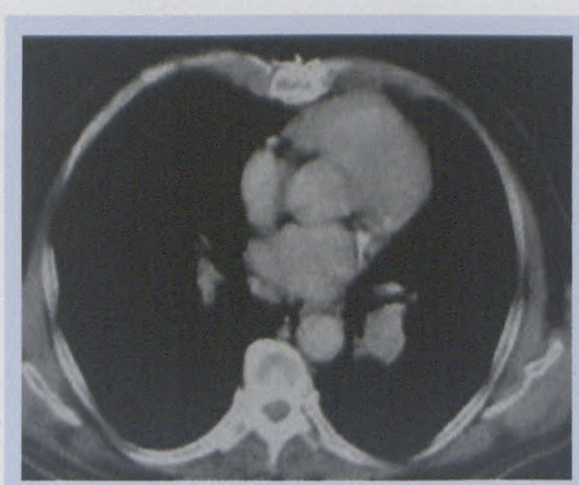

Fig. 6. Small tumour LLL but close to LUL bronchus therefore pneumonectomy rather than lobectomy required.

\section{Conclusion}

The radiological assessment of lung cancer requires an understanding of the biological behaviour of the disease, and a knowledge of the methods available to study it. Critical information required by the surgeon revolves around staging the primary tumour and assessing its resectability based on the information provided above. Accurate interpretation of the information requires practice and team work between the radiologist and the thoracic surgeon.

Although clinical staging under stages the disease in approximately $25 \%$ of cases, it is not an unacceptable situation, as it means that with the current system no patient with resectable disease will be denied a potentially curative resection.

Standardised reporting of the information needs to include a detailed description of the tumour based on the TNM system, and using an agreed upon nomenclature for the lymph nodes based on one of the available lymph node maps. It should also include any co-existing disease that may be used in the overall risk assessment for any planned therapy. Finally, the data should be recorded as accurately as possible for the purpose of later comparisons, used in assessing the response to therapy or the accuracy of clinical staging.

\section{References}

1. Pisani P, Parkin DM, Bray F, Ferlay J. Estimates of the worldwide mortality from 25 cancers in 1990. Int J Cancer 1999; 83: 18-29.

2. Travis WD, Lubin J, Ries L, Devesa S. United States lung carcinoma incidence trends: declining for most histologic cell types among males. increasing among females. Cancer 1996; 77: 2464-2470.

3. Martini N, Bains S, Burt M, et al. Incidence of local recurrence and second primary tumours in resected stage I lung cancer. I Thorac Cardiovasc Surg 1995; 109: 120-128.

4. Mountain CF. Revisions in the international system for staging lung cancer. Chest 1997; 111: 1710-1717.

5. Webb WR, Gatsonis C, Zerhouni EA, et al. CT and MRI imaging in staging non-small cell bronchogenic carcinomas: report of the Radiologic Diagnostic Oncology Group. Radiology 1991; 178: 705-713.

6. Isbicki JR, Thetter O, Karg O, et al. Accuracy of computed tomographic scan and surgical assessment for the staging of bronchial carcinoma. A prospective study. J Thorac Cardiovasc Surg 1992; 104: 413-420.

7. Herman SJ, Winton TL, Weisbrod GL, Towers MJ, Mentzer SJ. Mediastinal invasion by bronchogenic carcinoma: CT signs. Radiology 1994; 190: 841-846.

8. Naruke T, Suemasu K, Ishikawa S. Lymph node mapping and curability at various levels of metastasis in resected lung cancer. $J$ Thoracic Cardiovasc Surg 1978; 76: 833-839.

9. Mountain CF, Dresler CM. Regional lymph node classification for lung cancer staging. Chest 1997; 111: 1718-1723.

10. Korobkin M. CT characterisation of adrenal masses: the time has come. Radiology 2000; 217 629-632.

11. Miller DG, Crovello M, Mattteucci T, Petersen RO, Miettinen MM. Benign adrenocortical masses: diagnosis with chemical shift MRI imaging. Radiology 1992; 185: 345-351.

12. Lowe VJ, Naunheim KS. Positron emission tomography in lung cancer. Ann Thorac Surg 1998; 65: 1821-1829.

13. Goldstraw P, Mannam G, Kaplan D, Michail P. Surgical management of non-small cell lung cancer with ipsilateral mediastinal nodal metastasis (N2 disease). J Thorac Cardiovasc Surg 1994; 107: 19-27. 